\title{
Syntheses, Structures, and Mesomorphism of a Series of Cu(II) Salen Complexes with 4-Substituted Long Alkoxy Chains
}

\author{
Y. Abe \\ N. Nakazima \\ T. Tanase
}

Department of Chemistry, Faculty of Science, Nara Women's University, KitauoyaNishimachi, Nara 630-8506, Japan

\section{S. Katano \\ H. Mukai \\ K. Ohta}

Department of Functional Polymer Science, Faculty of Textile Science \& Technology, Shinshu University, Ueda 386-8567, Japan

\begin{abstract}
A series of copper(II) salen complexes containing 4-substituted alkoxy chains of aromatic rings, $\left[\mathrm{Cu}\left(\left(4-\mathrm{C}_{n} \mathrm{H}_{2 n+1} \mathrm{O}\right)_{2}\right.\right.$ salen) $](n=3$ (1), 4 (2), 6 (3), 8 (4), 10 (5), 12 (6), 14 (7), 16 (8), 18 (9), and 20 (10) ) and salen= $N, N^{\prime}$-ethylenebis(salicylideneiminato)) has been prepared and single crystal structures of $2 \cdot \mathrm{H}_{2} \mathrm{O}, \mathbf{4}$, and $\mathbf{6}$ by an X-ray crystallographic analysis have been revealed. Complexes $\mathbf{4}$ and $\mathbf{6}$ form tetrahedrally distorted square planer structure with onedimensional polymeric stacking by van der Waals interaction between the dramatically distorted salen moieties. Complexes 1 - 3 did not exhibit any mesophases, but complexes 4-10 with longer alkoxy chains of $n=8-20$ showed the metallomesogen of a lamellocolumnar (ColL) mesophase in the smectic layers with the nearly constant stacking distances,
\end{abstract}


irrespective of the variation of the alkoxy chain lengths by the X-ray diffraction measurements, which show similar behaviors to the corresponding $\mathrm{Ni}$ (II) complexes of $n=14-20$. The molecular assemblies and mesomorphic properties in relation to the single crystal structures of $\mathbf{4}$ and $\mathbf{6}$ with the liquid crystals at higher temperature are discussed.

\section{Keywords}

$\mathrm{Cu}$ (II) complexes, salen ligand with 4-substituted long alkoxy chains, crystal structure, metallomesogen

\section{INTRODUCTION}

Liquid crystals with transition-metal core groups, called as metallomesogens, have attracted increasing attention because of the possibility of combining their physico-chemical properties of the metal (color, magnetism, polarizability, redox behavior, etc) with those of organic framework [1-5]. Since the metallomesogens are achieved through changes of molecular conformation, shape, and structure, their physico-chemical properties can be turned by the choice of metal ions, substituents, and position of substituents on core moieties [6-8]. Schiff base ligands provide a wide range of ways to modify liquid crystal compounds [9-15]. However, to date there has been no systematic investigation concerning molecular assemblies and metallomesogens of metal-salen (salen $=N$, $N$ '-ethylenebi(salicylideneiminato)) complexes substituted by two long alkoxy chains at the 4-positions though the metal-salen complexes with 5-substituted alkoxy or alkyl chains usually show smectic $A\left(\mathrm{~S}_{\mathrm{A}}\right)$ mesophases at higher temperature [11-15]. In the previous papers, we prepared two series of the VO(IV) and Ni(II) salen complexes with two long alkoxy chains introduced at the 4positions, [VO $\left(\left(4-\mathrm{C}_{n} \mathrm{H}_{2 n+1} \mathrm{O}\right)_{2}\right.$ salen $\left.)\right]$ [16-17] and $\left[\mathrm{Ni}\left(\left(4-\mathrm{C}_{n} \mathrm{H}_{2 n+1} \mathrm{O}\right)_{2}\right.\right.$ salen)] [18] $(n=3-20)$, and found new mesomorphism of the VO(IV) salen complexes with $n=16-20$, which was unambiguously elucidated in relation to the bilayer crystal structure assembled by the 
VO(IV) complex. The Ni(II) salen complexes with longer alkoxy chains of $n=14-20$ showed an unusual metallomesogen of a lamello-columnar (ColL) mesophase. For the Ni(II) complexes, in the absence of diffraction quality crystals for any of the longer alkoxy chains ( $n \geqq 14$ ) homologues, the parent complex $\left[\mathrm{Ni}\left((4-\mathrm{OH})_{2}\right.\right.$ saen $\left.)\right]$ and $\left[\mathrm{Ni}\left(\left(4-\mathrm{C}_{6} \mathrm{H}_{13} \mathrm{O}\right)_{2}\right.\right.$ salen $\left.)\right]$ could be considered as model compounds and molecular assemblies taken as being representative for the discussion of the liquid crystal states of similar mesomorphic complexes. In the present work, a series of $\mathrm{Cu}(\mathrm{II})$ salen complexes with two 4-substituted long alkoxy chains, $\left[\mathrm{Cu}\left(\left(4-\mathrm{C}_{n} \mathrm{H}_{2 n+1} \mathrm{O}\right)_{2}\right.\right.$ salen $\left.)\right](n=3$ (1), 4 (2), 6 (3), 8 (4), 10 (5), 12 (6), 14 (7), 16 (8), 18 (9), and $20(\mathbf{1 0})$ ) has been prepared and fortunately, the single crystal structures of $\mathbf{4}$ and $\mathbf{6}$ with the mesomorphism at higher temperature have been revealed by an X-ray crystallographic analysis. The structures in liquid crystalline state with the ColL mesophase have been affiliated with the molecular assemblies in the crystalline states. The comparisons of the $\mathrm{Cu}(\mathrm{II})$ and $\mathrm{Ni}(\mathrm{II})$ complexes with the ColL mesophase [18] are discussed. There are few reports on the metallomesogen of the ColL mesophase [19-21].

\section{EXPERIMENTAL}

\section{Reagents and Measurements}

All chemicals and solvents for the synthesis were used without further purification of reagent grade. Organic solvents of superfine reagent grade were dried over molecular sieves prior to use for the spectroscopic measurements and cyclic voltammetry measurements. Electronic absorption and infrared spectra were recorded on Shimadzu UV-240 spectrophotometer and JASCO FT/IR-8900 $\mu$ in KBr media, respectively. Hokuto Denko HZ-1A apparatus was used for cyclic voltammetry measurements. The measurements were carried out in $\mathrm{CH}_{2} \mathrm{Cl}_{2}$ solution containing $n-\mathrm{Bu}_{4} \mathrm{NClO}_{4}\left(0.1 \mathrm{~mol} \mathrm{dm}^{-3}\right)$ as a supporting electrolyte with a threeelectrode cell including a platinum working electrode, a platinum counter electrode, and an 
$\mathrm{Ag} / \mathrm{Ag}^{+}$reference electrode. The mesomorphic nature of the complexes has been studied using polarized optical microscopy equipped with a thermoregulator-controlled heating plate as well as with a Mettler FP980 and a FP82HT, and measured with differential scanning calorimetry on a Shimadzu DSC-50 and a Rigaku Thermoplus TG-8120. The temperaturedependent X-ray diffraction was measured using a Rigaku RAD with $\mathrm{CuK \alpha}$ radiation equipped with a thermoregulator-controlled heating plate [22].

Synthesis of $\left[\mathrm{Cu}\left(\left(4-\mathrm{C}_{n} \mathrm{H}_{2 n+1} \mathrm{O}\right)_{2}\right.\right.$ salen $\left.)\right]((n=3$ (1), 4 (2), 6 (3), 8 (4), 10 (5), 12 (6), 14 (7), $16(8), 18(9)$, and $20(10))$

Ethylenediamine $(3.0 \mathrm{~g}, 0.050 \mathrm{~mol})$ was added to a solution of 2,4-dihydroxybenzaldehyde (13.8 $\mathrm{g}, 0.10 \mathrm{~mol})$ in methanol $(150 \mathrm{~mL})$ and stirred at $60{ }^{\circ} \mathrm{C}$ for $2 \mathrm{~h}$. The obtained (4$\mathrm{OH})_{2} \mathrm{SalenH}_{2}$ was collected and washed with diethyl ether. A mixture of $(4-\mathrm{OH})_{2} \mathrm{SalenH}_{2}(27$ $\mathrm{g}, 0.090 \mathrm{~mol})$ and $\mathrm{Cu}\left(\mathrm{CH}_{3} \mathrm{COO}\right)_{2} \cdot \mathrm{H}_{2} \mathrm{O}(19.0 \mathrm{~g}, 0.095 \mathrm{~mol})$ in the presence of $\mathrm{CH}_{3} \mathrm{COONa}$ in ethanol $(150 \mathrm{~mL})$ was stirred at room temperature for $24 \mathrm{~h}$. The preciptated $[\mathrm{Cu}((4-$ $\mathrm{OH})_{2}$ salen)](11) was filtered off and washed with ethanol, and diethyl ether. The reaction of 11 (3.6 g, $10 \mathrm{mmol})$ with $\mathrm{BrC}_{n} \mathrm{H}_{2 n+1}(n=3,4,6,8,10,12,14,16,18$, or 20) (40 mmol) in the presence of $\mathrm{K}_{2} \mathrm{CO}_{3}$ in DMF $(100$ - $200 \mathrm{~mL})$ for several days afforded [Cu((4$\left.\mathrm{C}_{n} \mathrm{H}_{2 n+1} \mathrm{O}\right)_{2}$ salen)] ( $n=3$ (1), 4 (2), 6 (3), 8 (4), 10 (5), 12 (6), 14 (7), $16(8), 18$ (9), or 20 (10)). After evaporation of solvent, dark violet precipitate was isolated by filtration, washed with methanol and diethyl ether. Crude complexes were purified by passing a silica-gel column with eluents of $\mathrm{CH}_{2} \mathrm{Cl}_{2}: \mathrm{MeOH}(20-25: 1(\mathrm{v} / \mathrm{v}))$. Elemental Anal. Calc. for $\mathrm{C}_{22} \mathrm{H}_{26} \mathrm{~N}_{2} \mathrm{O}_{4} \mathrm{Cu} \cdot \mathrm{H}_{2} \mathrm{O}$ (1) (446.02): C, 56.96, H, 6.08, N, 6.04. Found: C, 59.90; H, 6.05; N, 6.01\%. Yield $70 \%$. Calc. for $\mathrm{C}_{24} \mathrm{H}_{30} \mathrm{~N}_{2} \mathrm{O}_{4} \mathrm{Cu}$ (2) (474.06): C, 60.81; H, 6.38; N, 5.91. Found: C, 60.90; H, 6.30; N, $5.85 \%$. Yield $70 \%$. Calc. for $\mathrm{C}_{28} \mathrm{H}_{38} \mathrm{~N}_{2} \mathrm{O}_{4} \mathrm{Cu}(3)$ (530.17): C, 63.43, H, 7.22, N, 5.28. Found: C, 63.16; H, 7.19; N, $5.24 \%$. Yield $60 \%$. Calc. for $\mathrm{C}_{32} \mathrm{H}_{46} \mathrm{~N}_{2} \mathrm{O}_{4} \mathrm{Cu}(4)$ 
(586.28): C, 65.56, H, 7.91, N, 4.78. Found: C, 65.42; H, 7.86; N, $4.81 \%$. Yield 60 \%. Calc. for $\mathrm{C}_{36} \mathrm{H}_{54} \mathrm{~N}_{2} \mathrm{O}_{4} \mathrm{Cu}$ (5) (642.39): C, 67.16, H, 8.43, N, 4.31. Found: C, 67.31; H, 8.47; N, $4.36 \%$. Yield 50 \%. Calc. for $\mathrm{C}_{40} \mathrm{H}_{62} \mathrm{~N}_{2} \mathrm{O}_{4} \mathrm{Cu}$ (6) (698.49): C, 68.78, H, 8.95, N, 4.01. Found: C, 68.65; H, 8.89; N, 3.99 \%. Yield $40 \%$. Calc. for $\mathrm{C}_{44} \mathrm{H}_{70} \mathrm{~N}_{2} \mathrm{O}_{4} \mathrm{Cu}$ (7) (754.60): C, 70.04, H, 9.35, N, 3.71. Found: C, 69.73; H, 9.27; N, $3.67 \%$. Yield $30 \%$. Calc. for $\mathrm{C}_{48} \mathrm{H}_{78} \mathrm{~N}_{2} \mathrm{O}_{4} \mathrm{Cu}(8)$ (810.71): C, 71.11, H, 9.70, N, 3.46. Found: C, 70.68; H, 9.59; N, $3.41 \%$. Yield $20 \%$. Calc. for $\mathrm{C}_{52} \mathrm{H}_{86} \mathrm{~N}_{2} \mathrm{O}_{4} \mathrm{Cu}$ (9) (866.82): C, 72.05, H, 10.00, N, 3.23. Found: C, 71.89; H, 9.93; N, 3.21\%. Yield $15 \%$. Calc. for $\mathrm{C}_{56} \mathrm{H}_{94} \mathrm{~N}_{2} \mathrm{O}_{4} \mathrm{Cu}(\mathbf{1 0})(922.92): \mathrm{C}, 72.34, \mathrm{H}$, 10.35, N, 2.83. Found: C, 72.88; H, 10.27; N, $3.04 \%$. Yield $10 \%$.

\section{X-ray Crystallographic Analyses}

Single crystals of $\mathbf{2} \cdot \mathrm{H}_{2} \mathrm{O}, \mathbf{4}$, and $\mathbf{6}$ suitable for X-ray crystallography were obtained from the slow evaporation of $\mathrm{CH}_{2} \mathrm{Cl}_{2}$ solutions. The crystal data and experimental conditions are summarized in Table 1. All data were collected at $-120^{\circ} \mathrm{C}$ on a Rigaku/MSC Mercury CCD diffractometer equipped with graphite-monochromated $\mathrm{MoKa}$ radiation using a rotating-anode X-ray generator. A total of 2160 oscillation images, covering a whole sphere of $2 \theta<55^{\circ}$, were collected with exposure rates of $128 \mathrm{sec} /{ }^{\circ}$ by the $\omega$ scan method ($\left.62<\omega<118^{\circ}\right)$ with $\Delta \omega$ of $0.25^{\circ}$. The crystal-to-detector $(70 \times 70 \mathrm{~mm}$ ) distance was set to $60 \mathrm{~mm}$. The data were processed using the Crystal Clear 1.3.5 program (Rigaku/MSC) [23(a)] and corrected for Lorentz-polarization and absorption effects. The structures of 2 • $\mathrm{H}_{2} \mathrm{O}$, and 4 and $\mathbf{6}$ were solved by direct methods (SIR92) [23(b)] and Patterson method (DIRDIF PATTY), respectively, and refined on $F$ with the full-matrix least-squares techniques using the teXsan crystallographic software package [23(c)]. All non-hydrogen atoms were refined with anisotropic thermal parameters, and the positions of the hydrogen atoms were calculated with $\mathrm{C}-\mathrm{H}=0.95 \AA$ and fixed in the refinement. All calculations 
were carried out on a Silicon Graphics O2 workstation running teXsan and on a Pentiumbased PC running the Crystal Structure package [23(d)].

\section{RESULTS AND DISCUSSION}

\section{Synthesis and Characterization}

The stoichiometry and purity of all complexes were confirmed using elemental analyses, UV-vis and IR spectroscopies, and cyclic voltammetry (CV). Single crystal X-ray analysis of $\left[\mathrm{Cu}\left(\left(4-\mathrm{C}_{n} \mathrm{H}_{2 n+1} \mathrm{O}\right)_{2} \mathrm{Salen}\right)\right]\left(2 \cdot \mathrm{H}_{2} \mathrm{O}(n=4), 4(n=8)\right.$, and $\mathbf{6}(n=12)$ was performed. The UV-vis spectra of 1-11 exhibit d-d transitions $\left(\lambda_{3 \max }\right)$ in addition to strong metal-to-metal charge transfer (LMCT) bands $\left(\lambda_{2 \max }\right)$ and $n-\pi$ transitions in the ligand $\left(\lambda_{1 \max }\right)$ (Table 2$)$. Since cyclic voltammogram $(\mathrm{CV})$ showed the irreversible $\mathrm{Cu}(\mathrm{III}) / \mathrm{Cu}(\mathrm{II})$ couples, the values of the oxidation waves $\left(E_{\mathrm{ox}}\right)$ are summarized in Table 2. The data of UV-vis and cyclic voltammogram $(\mathrm{CV})$ are approximately constant regardless of the variation of the alkoxy chain lengths in a series of the $\mathrm{Cu}(\mathrm{II})$ complexes. IR data were similar to those of $[\mathrm{Ni}((4-$ $\left.\mathrm{C}_{n} \mathrm{H}_{2 n+1} \mathrm{O}\right)_{2}$ salen)] [18].

\section{Crystal structures of $2 \cdot \mathrm{H}_{2} \mathrm{O}(\mathrm{n}=4), 4(\mathrm{n}=8)$, and $6(\mathrm{n}=12)$}

Molecular structures and crystal packings of $2 \cdot \mathrm{H}_{2} \mathrm{O}$ and $\mathbf{6}$ are shown in Figure 1 (a) and (b), and Figure 2 (a) and (b), respectively, and those of 4 are deposited in Figure 3. The selected bond distances and angles, and dihedral angles are summarized in Table 3. Complex $2 \cdot \mathrm{H}_{2} \mathrm{O}$ forms an extremely distorted square-pyramidal structure by the apical coordination of the $\mathrm{H}_{2} \mathrm{O}$ molecule to the $\mathrm{Cu}$ metal center with dihedral angles of $18.744^{\circ}$ between the basal $\mathrm{N}_{2} \mathrm{O}_{2}$ plane and aromatic rings (Figure 1(a)). The Cu atom is displaced by $0.1898 \AA$ from the $\mathrm{N}_{2} \mathrm{O}_{2}$ plane toward apical oxygen atom of $\mathrm{H}_{2} \mathrm{O}$. On the basis of the Jahn-Teller effect, the apical $\mathrm{Cu}-\mathrm{O} 3$ distance $(2.296 \AA)$ is longer than the $\mathrm{Cu}-\mathrm{O}(1.944 \AA)$ and $\mathrm{Cu}-\mathrm{N}(1.959 \AA)$ distances 
in the basal $\mathrm{N}_{2} \mathrm{O}_{2}$ plane. On the other hand, [Cu(salen)] exists as dimers intermolecularly bridged through phenoxo oxygen atoms between the $\mathrm{Cu}$ atoms, forming the pair-wise link by two $\mathrm{Cu}$ and two $\mathrm{O}$ atoms [24-25]. Copper adopts tetragonally distorted square-pyramidal structure. The $\mathrm{Cu}$ atom is displaced by $0.14 \AA$ toward the bridging oxygen atom with asymmetrical dihedral angles of $24.9^{\circ}$ and $3.1^{\circ}$ between the $\mathrm{N}_{2} \mathrm{O}_{2}$ plane and aromatic rings [25]. While two $\mathrm{Cu}-\mathrm{N}$ distances $(1.958 \AA)$ are equal, two $\mathrm{Cu}-\mathrm{O}$ distances (1.945 $\AA$ and 1.911 $\AA$ ) show significant difference in the $\mathrm{N}_{2} \mathrm{O}_{2}$ plane. The apical (bridged) $\mathrm{Cu}-\mathrm{O}$ distance $(2.414$ $\AA$ ) is longer than those of the basal plane as well as that of $\mathbf{2} \cdot \mathrm{H}_{2} \mathrm{O}$. The significant difference of the bond distances and dihedral angles between $2 \cdot \mathrm{H}_{2} \mathrm{O}$ and $[\mathrm{Cu}($ salen) $]$ is due to the monomer for $\mathbf{2} \cdot \mathrm{H}_{2} \mathrm{O}$ and the dimer for [Cu(salen)] in a distorted square-pyramidal structure, depending on the presence and absence of the substituents at the 4-positions of aromatic rings. On the other hand, in the case of [Ni(salen)], the structure forms face-to-face dimer separated by $3.08 \AA$ with weak $\pi-\pi$ stacking which is not intermolecularly bridged between the phenoxo oxygen atoms and the $\mathrm{Ni}$ atoms [26]. The difference of these structures may be due to the preference of the square planar structure of $[\mathrm{Ni}(\mathrm{salen})]$ as compared to $[\mathrm{Cu}($ salen $)]$.

Molecular structure and crystal packing of 4 resemble to those of 6 (Figures 2 and 3). Complex 4 and 6 have tetrahedrally distorted square planar structure composed of the significantly distorted salen moieties with dihedral angles of $23.856^{\circ}$ and $23.829^{\circ}$ between the basal $\mathrm{N}_{2} \mathrm{O}_{2}$ plane and aromatic rings, respectively. The $\mathrm{Cu}$ atom sites at $0.2511 \AA$ and $0.2931 \AA$ from the $\mathrm{N}_{2} \mathrm{O}_{2}$ plane for 4 and 6, respectively. The $\mathrm{Cu}-\mathrm{O}(1.905-1.906 \AA)$ and $\mathrm{Cu}-$ $\mathrm{N}(1.931-1.934 \AA)$ distances are relatively short in comparison to those of $\mathbf{2} \cdot \mathrm{H}_{2} \mathrm{O}$ and $[\mathrm{Cu}$ (salen)]. This difference is based on a square planar structure for $\mathbf{4}$ and $\mathbf{6}$ as contrast with a square-pyramidal structure for $\mathbf{2} \cdot \mathrm{H}_{2} \mathrm{O}$ and $[\mathrm{Cu}($ salen) $]$. The molecular packings of 4 and $\mathbf{6}$ are consisted of the face-to-face structure by one-dimensional polymeric stacking 
formed by van der Waals interaction of ca. 3.3-3.5 $\AA(\mathrm{Cu}(1) \cdots \mathrm{C}(3)=3.305 \AA, \mathrm{Cu}(1) \cdots$ $\mathrm{C}(2)=3.311 \AA, \mathrm{C}(1) \cdots \mathrm{C}(4)=3.514 \AA, \mathrm{O}(1) \cdots \mathrm{C}(2)=3.350 \AA)$ between the distorted salen moieties with the $\mathrm{Cu}-\mathrm{Cu}$ distance of $4.8162 \AA$ and $4.9061 \AA$, respectively (Figures 2 and 3). On the other hand, in the crystal of the Ni(II) complex with two alkoxy chains $(n=6)$ at the 4 potisions, two molecules (A, B) with slightly different bond distances and angles are present [18]. Two aromatic rings of $\mathbf{A}$ or $\mathbf{B}$ are not coplanar to each other with the dihedral angles of $14.501^{\circ}$ and $7.764^{\circ}(\mathbf{A})$ or $13.468^{\circ}$ and $8.158^{\circ}(\mathbf{B})$ relatively smaller than those of $4(23.856$ $\left.{ }^{\circ}\right)$ and $6\left(23.829^{\circ}\right)$. Moreover, the molecules are organized by a set of weak $\mathrm{C}-\mathrm{H} \cdots \mathrm{O}$ type hydrogen bonded interaction between neighboring molecules with a dihedral angle of $59.570^{\circ}$ between the $\mathrm{N}_{2} \mathrm{O}_{2}$ plane of $\mathbf{A}$ and the $\mathrm{N}_{2} \mathrm{O}_{2}$ plane of $\mathbf{B}$. The stacking leads to onedimensional structure with the Ni-Ni distance of $5.994 \AA$.

In the solid states of $\left[\mathrm{Cu}\left(\left(5-\mathrm{CH}_{3} \mathrm{O}\right)_{2}\right.\right.$ salen $\left.)\right]$ with 5-substituted alkoxy groups, the molecules form weak dimeric structure as well as $[\mathrm{Cu}$ (salen)] [25]. The $\mathrm{Cu}$ atom is displaced by only $0.06 \AA$ toward the bridging phenoxo oxygen atom with smaller asymmetrical dihedral angles of $14.5^{\circ}$ and $9.9^{\circ}$ than those of $[\mathrm{Cu}(\mathrm{salen})]$. The apical (bridged) $\mathrm{Cu}-\mathrm{O}$ distance $(2.801 \AA)$ is relatively long in comparison of that $(2.414 \AA)$ of $[\mathrm{Cu}($ salen $)]$. On the other hand, the dimeric structure of $\left[\mathrm{Cu}\left(\left(5-\mathrm{C}_{6} \mathrm{H}_{13} \mathrm{O}\right)_{2} \mathrm{salen}\right)\right] \cdot \mathrm{CHCl}_{3}$ is the co-planar to each other between the $\mathrm{N}_{2} \mathrm{O}_{2}$ plane and aromatic rings [27]. Moreover, the dimeric structure consists of isolated molecules with weak pair-wise link between the $\mathrm{Cu}$ atoms and the alkoxy oxygen atoms at the 5-positions $(3.53 \AA)$ of the adjacent molecules. The molecular pairs so formed are further linked into pseudo-polymeric chains by weaker (4.01 $\AA$ ) interactions of the outer alkoxy oxygens with the $\mathrm{Cu}$ atoms of adjacent pairs. Thus, the geometry and assembly for $\left[\mathrm{Cu}\left(\left(4-\mathrm{C}_{n} \mathrm{H}_{2 n+1} \mathrm{O}\right)_{2}\right.\right.$ salen $\left.)\right](n=8,12)$, and $[\mathrm{Cu}((5-$ $\left.\mathrm{C}_{6} \mathrm{H}_{13} \mathrm{O}\right)_{2}$ salen)] $\cdot \mathrm{CHCl}_{3}$ depend significantly on the positions of substituents on the aromatic rings, leading to the different mesomorphic properties at higher temperature as described 
below.

\section{Mesomorphic properties of $4(n=8)-10(n=20)$}

The mesomorphic nature of complexes has been studied by three methods using polarized optical microscopy, differential scanning calorimetry (DSC), and temperature-dependent Xray diffraction (XRD) measurements [28]. From these measurements, complexes $\mathbf{1}-\mathbf{3}$ did not exhibit the mesomorphic property. On the other hand, the crystalline phases for $\mathbf{4}-\mathbf{1 0}$ were transformed into phases with mosomorphic nature. The natural texture of $\mathbf{1 0}(n=20)$ is shown in Figure 4. Figure 4 shows the X-ray patterns for the enantiotropic mesophase of $7(n=14)$ at $140{ }^{\circ} \mathrm{C}$ by $\mathrm{XRD}$ measurements as one example, which are very similar to the X-ray patterns of the planar $\mathrm{Ni}$ (II) complexes of $n=14-20$ with a lamello-columnar (ColL) mesophase [18] rather than those of the pyramidal $\mathrm{VO}(\mathrm{IV})$ complexes of $n=16-20$ [16-17]. X-ray patterns have three arrow reflections (No. 1-3) in the low-angle region blow $10^{\circ}$ and their spacing in a ratio of $1: 1 / 2: 1 / 3$ which correspond to the (001), (002), and (003) planes with a lamellar distance $c$ (Figure 5 and Table 5). A diffuse band around $20^{\circ}$ (No. 5) is due to the melting of alkoxy chains. With these reflections, the X-ray pattern possesses an additional peak at $14^{\circ}$ (No. 4), indicating that the X-ray pattern for this mesophase affords the stacking distance in a columnar structure in addition to the lamellar structure. Thus, this mesophase has both lamellar and columnar structures corresponding the lamello-columnar (ColL) mesophase with a stacking distance $h$ in the $a$ axis direction. The stacking distances $h=6.02-6.12 \AA$ for $\mathbf{5}-\mathbf{1 0}$ are independent of the variation of the alkoxy chain lengths. This stacking distances well correspond to the distance between the inter-molecules with the alkoxy chains in the same direction. Thus, the stacking distances between the monomers are attributed to be ca. $3 \AA$. The lamellar distance $c$ with $25.5-41.2 \AA$ for $\mathbf{5 - 1 0}$ is linear to the number of carbon atoms in the alkoxy chain $(n)$ with the slope of 1.56 (Figure 6), which may tilt toward the layer. Hence, 
schematic representation of the ColL mesophase of $\mathbf{5 - 1 0}$ can be illustrated as Figure 7. The Ni(II) complexes with $n=10-20$ exhibit the similar behaviors to the CuII) complexes which show the lamello-columnar mesophase. The $h$ values for the $\mathrm{Cu}(\mathrm{II})$ complexes are a slightly smaller than those $(6.20-6.24 \AA)$ for the Ni(II) complexes, but the slope of the lamellar distances is a slightly larger than that of the Ni(II) complexes with 1.44. If the Miller index of (100) were not present in this mesophase, this mesophase would be regarded as the smectic mesophase. The ColL mesophase possesses an unusual columnar phase with the onedimensional ordering of molecules within the smectic layers. There are few reports on the metallomesogen of the ColL mesophase [19-21]. For the ColL mesophase with the linear rodlike molecules, the distance attributed to the stacking between the aromatic rings in the monomers was measured directly as $c a .3 .4 \AA$ [21]. In the case of the $\mathrm{Cu}(\mathrm{II})$ complexes, the absence of the peak attributed to $c a .3 .4 \AA$ may depend on the structure of the $\mathrm{Cu}(\mathrm{II})$ complex with 4-substituted alkoxy groups with the U-shaped structure without the linear rod-like structures.

The X-ray crystal structures for $\mathbf{4}$ and $\mathbf{6}$ can be available for the discussion on the liquid crystal states since $\mathbf{4}$ and $\mathbf{6}$ show the mesomorphic property at high temperature. The molecular assemblies of the prototypes of the complexes exhibit notable features when the crystalline phase transforms into the liquid crystalline phase [17, 27]. The molecular packing of $\mathbf{6}$ is consisted of one-dimensional polymeric stacking formed by van der Waals interaction of 3.3-3.5 $\AA$ with the face-to-face between the salen cores as described above (Figure 2). When this crystal is transferred into the liquid crystal, the stacking distance in the liquid crystal shows ca $3 \AA$ slightly smaller than 3.3-3.5 $\AA$. This result suggests that the change from the dramatically distorted salen moieties in the crystal to the almost planer salen moieties in this ColL mesophase occurs at higher temperature above $130{ }^{\circ} \mathrm{C}$, leading to the more approach of the distance between the salen moieties. Thus, the stacking distance with ca. $3 \AA$ 
at higher temperature may be adequate to this ColL structures. The apical (bridged) $\mathrm{Cu}-\mathrm{O}$ distance in dimer for $[\mathrm{Cu}$ (salen) $]$ is $2.414 \AA$ considerably shorter than ca. $3 \AA$. The $\mathrm{Cu}-\mathrm{Cu}$ distance may be longer than ca. $3 \AA$ as shown in Figure 7.

Phase transition temperatures and enthalpy changes for $\left[\mathrm{Cu}\left(\left(4-\mathrm{C}_{n} \mathrm{H}_{2 n+1} \mathrm{O}\right){ }_{2}\right.\right.$ salen $\left.)\right]$ $(n=3-20)$ obtained by DSC measurements are summarized in Table 4. All the complexes exhibit the appearance of the isomeric crystal phases during the formation of isotropic liquid. The dependence of the number of carbon atoms in the alkoxy chain ( $n$ ) for the 4-alkoxysalen on the phase transition temperature is shown with the data for $\left[\mathrm{Ni}\left(\left(4-\mathrm{C}_{n} \mathrm{H}_{2 n+1} \mathrm{O}\right)_{2} \mathrm{salen}\right)\right]$ [18] in Figure 8. The transition temperature from the crystalline phase or the ColL mesophase to isotropic liquid (I.L.) decreases gradually upon increasing the number of carbon atoms $(n)$ in accordance with the Ni(II) homologues. However, the occurrence of the ColL mesophase of $\left[\mathrm{Cu}\left(\left(4-\mathrm{C}_{n} \mathrm{H}_{2 n+1} \mathrm{O}\right)_{2}\right.\right.$ salen $\left.)\right]$ exhibits at the alkoxy chain lengths shorter than that of $[\mathrm{Ni}((4-$ $\left.\mathrm{C}_{n} \mathrm{H}_{2 n+1} \mathrm{O}\right)_{2}$ salen)]. This may be due to the difference of the molecular packings as described in above section. For $5-\mathbf{1 0}$, the enthalpy changes $\left(\Delta H_{\text {clear }}=23.3-25.2 \mathrm{~kJ} \mathrm{~mol}^{-1}\right)$ from the liquid crystal phase ColL to I.L. at the clearing point are approximately independent of the alkoxy chain lengths (Table 4). The $\Delta H_{\text {clear }}$ values are comparable to those of $[\mathrm{Ni}((4-$ $\left.\mathrm{C}_{n} \mathrm{H}_{2 n+1} \mathrm{O}\right)_{2}$ salen $\left.)\right](n=14-20)\left(\Delta H_{\text {clear }}=23.9-25.5 \mathrm{~kJ} \mathrm{~mol}^{-1}\right)$. Though the occurrence of the ColL mesophase of $\left[\mathrm{Cu}\left(\left(4-\mathrm{C}_{n} \mathrm{H}_{2 n+1} \mathrm{O}\right)_{2}\right.\right.$ salen $\left.)\right]$ exhibits at the alkoxy chain lengths shorter than that of $\left[\mathrm{Ni}\left(\left(4-\mathrm{C}_{n} \mathrm{H}_{2 n+1} \mathrm{O}\right)_{2}\right.\right.$ salen $\left.)\right]$, similar enthalpy changes are based on the structure of the ColL mesophase with similar stacking distances of the $\mathrm{Cu}(\mathrm{II})$ and $\mathrm{Ni}(\mathrm{II})$ complexes irrespectveof the variation of the alkoxy chain lengths, because the enthalpy changes from the ColL mesophase to I.L. are generated from the rupture of the polymeric stacking between the cores. The enthalpy changes at the clearing point are considerably larger than these observed for the complexes with the shorter alkyl or alkoxy chains at the 5-position with the $\mathrm{S}_{\mathrm{A}}$ mesophase of the linear rod-like (1D) structure [9-15]. Because 5-10 with two longer alkoxy 
chains at the 4-positions exhibit ColL mesophase which shows the more ordered 2D rectangular mesophase than the $\mathrm{S}_{\mathrm{A}}$ mesophase of the linear rod-like (1D) structure. The enthalpy changes increase as the order in the mesophase increases because the interaction between the neighboring core groups is large in the $2 \mathrm{D}$ rectangular mesophase compared to the $\mathrm{S}_{\mathrm{A}}$ mesophase of the 1D structure [29]. Chipperfield et al. have reported (5-substituted troporonato)copper(II) complexes with aloxy chains with $18.42 \mathrm{~kJ} / \mathrm{mol}$ for $n=10$ and 26.80 $\mathrm{kJ} / \mathrm{mol}$ for $n=16$ in the transformation from isotropic liquid to the $\mathrm{S}_{\mathrm{B}}$ phase [27]. Furthermore, in general, complexes with the larger molecular weight and/or long alkoxy or alkyl chains exhibit larger enthalpy changes for the transition between phases [19(b), 27].

The Co(II), Ni(II), Cu(II), and VO(IV) salen complexes with 5-substituted alkoxy or alkyl chains of the aromatic rings usually show smectic $A\left(S_{A}\right)$ mesophases at higher temperature because of the linear rod-like (1D) crystal structures. The $\left[\mathrm{Ni}\left(\left(5-\mathrm{C}_{6} \mathrm{H}_{13}\right)_{2}\right.\right.$ salen $\left.)\right]$ complex transforms enantiotropically from dimer-smectic $\mathrm{E}\left(\mathrm{S}_{\mathrm{E}}\right)$ at lower temperature to monomer- $\mathrm{S}_{\mathrm{A}}$ mesophases at higher temperature [15]. However, new series of $\left[\mathrm{VO}\left(\left(4-\mathrm{C}_{n} \mathrm{H}_{2 n+1} \mathrm{O}\right)_{2} \mathrm{salen}\right)\right](n$ $=16-20)$ and $\left[\mathrm{Cu}\left(\left(4-\mathrm{C}_{n} \mathrm{H}_{2 n+1} \mathrm{O}\right)_{2}\right.\right.$ salen $\left.)\right](n=8-20)$ in addition to $\left[\mathrm{Ni}\left(\left(4-\mathrm{C}_{n} \mathrm{H}_{2 n+1} \mathrm{O}\right)_{2}\right.\right.$ salen $\left.)\right]$ $(n=14-20)$ with two alkoxy long chains introduced at 4-positions exhibit new mesophase $\mathrm{M}\left(\mathrm{Pa}_{1}\right)$ [16-17] and the ColL mesophase with the linear stacking structure [18], respectively. These liquid crystal structures are closely related with the molecular assemblies in the crystalline state when the crystalline phase transfers into the liquid crystalline phase.

\section{CONCLUTION}

Single crystal structures of $\mathbf{2} \cdot \mathrm{H}_{2} \mathrm{O}, \mathbf{4}$, and $\mathbf{6}$ by an X-ray crystallographic analysis have been revealed. The molecular assemblies and mesomorphic properties of the $\mathrm{Cu}(\mathrm{II})$ complexes with the ColL mesophase are affiliated with the single crystal structures of $\mathbf{4}$ and $\mathbf{6}$ with the mesomorphism at higher temperature. Since in contrast to the $\mathrm{Cu}(\mathrm{II})$ and $\mathrm{Ni}(\mathrm{II})$ complexes, 
the VO(IV) complexes with the square-pyramidal structure forms the mesophase $\mathrm{M}\left(P \mathrm{a} 2{ }_{1}\right)$ with the bilayer structure from the bilayer crystal structure, the assemblies and the mesomorphic properties depend remarkably on the selection of the metal ions and the positions of substituents on aromatic rings of salen moieties.

\section{ACKNOWLEDGEMENTS}

We are grateful to the Nara Women's University Intramural Grant for Project Research.

\section{SUPPLEMENTALY MATERIALS}

Crystallographic data for the structures reported in this paper are deposited with Cambridge Crystallographic Data center as supplementary publication No. CCDC 607247607249.

\section{REFERENCES}

*Author to whom correspondence should be addressed. E-mail: yabe@cc.nara-wu.ac.jp, TEL/FAX: +81-742-20-3394.

[1] B. Donnio, D. W. Bruce, in Structure and Bonding, (Ed.: D. M. P Mingos), Vol. 95, Liquid Crystals II. Metallomesogens, Springer (1999). (b) B. Donnio, D Guillon, R. Deschenaux, D. W. Bruce, "Metallomesogens" in Comprehensive Coordination Chemistry II. Vol. 6 (Eds.: J. A. McCleverty, T. J. Meyer), Elsevier: Oxford (2003)

[2] A-M. Giroud-Godquin, P. M. Maitlis, Angew. Chem. Int. Ed. Engl., 30, 375 (1991).

[3] M. H. Chisholm, Acc. Chem. Res., 33, 53 (2000).

[4] P. Kirsch, M. Bremer, Angew. Chem. Int. Ed. Engl., 39, 4216 (2000).

[5] I. Aiello, M. Ghedini, M. La Deda, D. Pucci, O. Francescangeli, Eur. J. Inorg. Chem., 
1367 (1999).

[6] (a) D. Pucci, G. Barberio, A. Crispini, O. Francescangeli, M. Ghedini, Mol. Cryst. Liq. Cryst., 395, 325 (2003). (b) G. Barberio, A. Bellusci, A. Crispini, M. Ghedini, A. Golemme, P. Prus, D. Pucci, Eur. J. Inorg. Chem., 181 (2005).

[7] X-H. Liu, M. N. Abser, D. W. Bruce, J. Organomet. Chem., 551, 271 (1998).

[8] A. B. Blake, J. R. Chipperfield, W. Hussain, R. Paschke, E. Sinn, Inorg. Chem., 34, $1125(1995)$.

[9] N. Hoshino, H. Murakami, Y. Matsunaga, T. Inabe, Y. Maruyama, Inorg. Chem., 29, 1177 (1990).

[10] (a) R. Paschke, H. Zaschke, A. Maedicke, J. R. Chipperfield, A. B. Blake, P. G. Nelson, G. W. Gray, Mol. Cryst. Liq. Cryst. Lett., 6, 81 (1988). (b) T. D. Shaffer, K. A. Sheth, Mol. Cryst. Liq. Cryst., 172, 27 (1989). (c) R. Paschke, D. Balkow, U. Baumeister, H. Hartung, J. R. Chipperfield, A. B. Blake, P. G. Nelson, G. W. Gray, Mol. Cryst. Liq. Cryst. 188, 105 (1990)

[11] R. Paschke, S. Diele, I. Letko, A. Wiegeleben, G. Pelzl, K. Grieser, M. Athanassopoulou, W. Haase, Liq. Cryst., 18, 451 (1995).

[12] R. Paschke, D. Balkow, E. Sinn, Inorg. Chem., 41, 1949 (2002).

[13] (a) A. Serrette, P. J. Carroll, T. M. Swager, J. Am. Chem. Soc., 114, 1887 (1992). b) Additions and Corrections: A. Serrette, P. J. Carroll, T. M. Swager, J. Am. Chem. Soc., 115, $11656(1993)$.

[14] A. G. Serrette, T. M. Swager, J. Am. Chem. Soc., 115, 8879 (1993).

[15] (a) K. Ohta, Y. Morizumi, T. Fujimoto, I. Yamamoto, K. Miyamura, Y. Gohshi, Mol. Cryst. Liq. Cryst., 214, 161 (1992). (b) K. Miyamura, A. Mihara, T. Fujii, Y. Gohshi, Y. Ishii, J. Am. Chem. Soc. 117, 2377 (1995).

[16] Y. Abe, K. Nakabayashi, N, Matsukawa, M. Iida, T. Tanase, M. Sugibayashi, H. Mukai, 
K. Ohta, Inorg. Chem. Commun., 7, 580 (2004).

[17] Y. Abe, K. Nakabayashi, N, Matsukawa, H. Takashima, M. Iida, T. Tanase, M. Sugibayashi, H. Mukai, K. Ohta, Inorg. Chim. Acta, 359, 3934 (2006).

[18] Y. Abe, H. Akao, Y. Yoshida, H. Takashima, T. Tanase, H. Mukai, K. Ohta, Inorg. Chim. Acta, 359, 3147 (2006).

[19] (a) J. Billard, C. R. Acad. Sc. Paris., 299, 905 (1984). (b) K. Ohta, H. Muroki, A. Takagi, K. Hatada, H. Ema, I. Yamamoto, and K. Matsuzaki, Mol. Cryst. Liq. Cryst., 140, 131 (1986).

[20] S. Mèry, D. Haristoy, J-F. Nicoud, D. Cuillon, S. Diele, H. Monobe, Y. Shimizu, J. Mater. Chem., 12, 37 (2002).

[21] A. El-ghayoury, L. Douce, A. Skoulios, R, Ziessel, Angew. Chem. Int. Ed., 37, 1255 (1998).

[22] H. Hasebe, Master Thesis, Shinshu University, Ueda, Japan, Chap. 5 (1991).

[23] (a) Crystal Clear 1.3.5: Operating software for the CCD detector system. Rigaku and Molecular Structure Corp. (2003). (b) A. Altomare, M. C. Burla, M. Camalli, M. Cascarano, C. Giacovazzo, A. Guagliardi, G. Polidori, J. Appl. Cryst., 27, 435 (1994). (c) TEXSAN: Crystal Structure Analysis Package, Molecular Structure Corp. (1999). (d) Crystal Structure 3.6: Crystal Structure Analysis Package, Rigaku and Molecular Structure Corp. (2003).

[24] E. N. Barker, D. Hall, T. N. Waters, J. Chem. Soc. (A)., 400 (1979); 406 (1979).

[25] M. M. Bhadbhade, D. Srinivas, Inorg. Chem., 32, 6122 (1993).

[26] (a) F.F. Dimauro and M. C. Kozoiowski, Organometallics, 21, 1454 (2003). (b) M. Kondo, K. Nabari, T. Horiba, Y. Irie, M. K. Kabir, R. P. Sarker, E. Shimizu, Y. Shimizu, Y. Fuwa, Inorg. Chem. Commun., 6, 154 (2003). c) X. Cheng, S. Gao, L. Huo, S. W. Ng, Acta. Cryst., E61, m385 (2005). 
[27] (a) J. R.Chipperfield, S. Clark, J. Elliott, E. Sinn, Chem. Commun., 195 (1998). (b) J. M. Elliott, J. R. Chipperfield, S. Clark, Inorg. Chem., 41, 293 (2002).

[28] F. Maeda, K. Hatsusaka, K. Ohta, M. Kimura, J. Mater. Chem., 13, 243 (2003).

[29] (a) K. Pelz. W. Weissflog, U. Baumeister, S. Diele, Liq. Cryst., 30, 1151 (2003). (b) D. Kardas. M. Prehm, U. Baumeister, D. Pociecha, R. A. Reddy, G. H. Mehl, C. Tschierske, J. Mater. Chem., 15, 1722 (2005). 
TABLE 1 Crystallographic and Experimental Data for $\left[\mathrm{Cu}\left(\left(4-\mathrm{C}_{n} \mathrm{H}_{2 n+1} \mathrm{O}\right)_{2}\right.\right.$ salen $\left.)\right]\left(n=4\left(2 \cdot \mathrm{H}_{2} \mathrm{O}\right), 8(4), 12\right.$ (6))

\begin{tabular}{|c|c|c|c|}
\hline & $2 \cdot \mathrm{H}_{2} \mathrm{O}$ & 4 & 6 \\
\hline Empirical formula & $\mathrm{C}_{24} \mathrm{H}_{32} \mathrm{CuN}_{2} \mathrm{O}_{5}$ & $\mathrm{C}_{32} \mathrm{H}_{46} \mathrm{CuN}_{2} \mathrm{O}_{4}$ & $\mathrm{C}_{40} \mathrm{H}_{62} \mathrm{CuN}_{2} \mathrm{O}_{4}$ \\
\hline Formula weight & 492.07 & 586.27 & 698.49 \\
\hline Crystal Color & green blue & pale brown & pale brown \\
\hline Crystal Dimens. / nm & $0.45 \times 0.30 \times 0.10$ & $0.40 \times 0.35 \times 0.05$ & $0.35 \times 0.15 \times 0.05$ \\
\hline Crystal System & orthorhombic & monoclinic & monoclinic \\
\hline Space group & $P$ nma(\#62) & $C 2 / \mathrm{c}(\# 15)$ & $C 2 / \mathrm{c}(\# 15)$ \\
\hline$a(\AA)$ & $8.8753(4)$ & $43.04(1)$ & $52.569(4)$ \\
\hline$b(\AA)$ & $34.267(2)$ & $7.211(2)$ & $7.3513(5)$ \\
\hline$c(\AA)$ & $7.5402(2)$ & $9.603(2)$ & $9.7909(5)$ \\
\hline$\beta(\operatorname{deg})$ & & $92.642(1)$ & $91.496(1)$ \\
\hline$V\left(\AA^{3}\right)$ & $2293.2(2)$ & $2976(1)$ & $3782.4(4)$ \\
\hline Z & 4 & 4 & 4 \\
\hline$D_{\text {calc }}\left(\mathrm{g} / \mathrm{cm}^{3}\right)$ & 1.425 & 1.308 & 1.226 \\
\hline$\mu(\mathrm{Mo}-\mathrm{K} \alpha)\left(\mathrm{cm}^{-1}\right)$ & 9.9 & 7.72 & 6.18 \\
\hline $2 \theta$ rang,deg & $6-55$ & $6-55$ & $6-55$ \\
\hline No.variables & 149 & 178 & 214 \\
\hline No observation & $2228(\mathrm{I}>2 \sigma(\mathrm{I}))$ & $2966(\mathrm{I}>2 \sigma(\mathrm{I}))$ & $2500(\mathrm{I}>2 \sigma(\mathrm{I}))$ \\
\hline temp. $\left({ }^{\circ} \mathrm{C}\right)$ & -120 & -120 & -120 \\
\hline Residuals $: R ; R w^{a}$ & $0.058 ; 0.133$ & $0.061 ; 0.140$ & $0.062 ; 0.163$ \\
\hline GOF & 1.08 & 1.16 & 1.13 \\
\hline
\end{tabular}

${ }^{a} R=\Sigma|| F_{0}|-| F_{\mathrm{c}}\left|/ \sum\right| F_{0} \mid \cdot R_{\mathrm{w}}=\left\{\left[\sum w\left(F_{0}^{2}-F_{\mathrm{c}}{ }^{2}\right)^{2}\right] / \Sigma\left[\left(w\left(F_{0}{ }^{2}\right)^{2}\right)\right]\right\}^{1 / 2}$ 
TABLE 2 Absorption Maxima and $E_{\text {ox }}$ Values for $\left[\mathrm{Cu}\left(\left(4-\mathrm{C}_{n} \mathrm{H}_{2 n+1} \mathrm{O}\right)_{2}\right.\right.$ salen) $](n=3(\mathbf{1}), 4(\mathbf{2}), 6(\mathbf{3}), 8(\mathbf{4}), 10$ $(\mathbf{5}), 12(\mathbf{6}), 14(\mathbf{7}), 16(\mathbf{8}), 18(\mathbf{9})$, and $20(\mathbf{1 0})$ and $\left[\mathrm{Cu}\left((4-\mathrm{HO})_{2}\right.\right.$ salen) $](\mathbf{1 1})$ in $\mathrm{CH}_{2} \mathrm{Cl}_{2}$

\begin{tabular}{lllllllll}
\hline Complex & $\mathrm{n}$ & $\lambda_{1 \max } / \mathrm{nm}$ & $\log \varepsilon$ & $\lambda_{2 \max } / \mathrm{nm}$ & $\log \varepsilon$ & $\lambda_{3 \max } / \mathrm{nm}$ & $\log \varepsilon$ & $E_{\text {ox }} / \mathrm{V} \mathrm{vs.} \mathrm{Ag-Ag}$ \\
\hline $\mathbf{1}$ & 3 & 292 & 4.459 & 351 & 3.983 & 566 & 2.623 & 0.61 \\
$\mathbf{3}$ & 4 & 292 & 4.513 & 351 & 4.016 & 564 & 2.638 & 0.62 \\
$\mathbf{4}$ & 6 & 292 & 4.428 & 351 & 3.954 & 564 & 2.609 & 0.61 \\
$\mathbf{5}$ & 8 & 292 & 4.477 & 349 & 4.010 & 566 & 2.602 & 0.62 \\
$\mathbf{6}$ & 10 & 292 & 4.480 & 349 & 3.983 & 566 & 2.634 & 0.63 \\
$\mathbf{7}$ & 12 & 292 & 4.476 & 351 & 3.981 & 566 & 2.615 & 0.63 \\
$\mathbf{8}$ & 14 & 290 & 4.506 & 351 & 4.034 & 566 & 2.622 & 0.63 \\
$\mathbf{9}$ & 16 & 290 & 4.450 & 351 & 4.005 & 566 & 2.603 & 0.62 \\
$\mathbf{1 0}$ & 18 & 290 & 4.449 & 351 & 3.973 & 566 & 2.612 & 0.63 \\
$\mathbf{1 1}$ & 20 & 292 & 4.501 & 349 & 4.004 & 566 & 2.601 & 0.62 \\
\hline
\end{tabular}

${ }^{\mathrm{a} D M F}$ was used. $\quad{ }^{\mathrm{b}} \mathrm{Scan}$ speed : $100 \mathrm{mV} / \mathrm{s}$. 
TABLE 3 Selected Bond Distances $(\AA)$ and Angles $\left({ }^{\circ}\right)$, and Dihedral Angles $\left({ }^{\circ}\right)$ for $\left[\mathrm{Cu}\left(\left(4-\mathrm{C}_{n} \mathrm{H}_{2 \mathrm{n}+1} \mathrm{O}\right)_{2}\right.\right.$ salen $\left.)\right]\left(n=4\left(2 \cdot \mathrm{H}_{2} \mathrm{O}\right), 8(4), 12(6)\right)$

\begin{tabular}{|c|c|c|c|}
\hline & $2 \cdot \mathrm{H}_{2} \mathrm{O}$ & 4 & 6 \\
\hline $\mathrm{Cu}-\mathrm{O} 1$ & $1.944(2)$ & $1.906(2)$ & $1.905(3)$ \\
\hline $\mathrm{Cu}-\mathrm{O} 1 *$ & $1.944(2)$ & $1.906(2)$ & $1.905(3)$ \\
\hline $\mathrm{Cu}-\mathrm{N} 1$ & $1.959(3)$ & $1.931(2)$ & $1.934(3)$ \\
\hline $\mathrm{Cu}-\mathrm{N} 1 *$ & $1.959(3)$ & $1.931(2)$ & $1.934(3)$ \\
\hline $\mathrm{Cu}-\mathrm{O} 3$ & $2.296(3)$ & & \\
\hline $\mathrm{O} 1-\mathrm{Cu}-\mathrm{O} 1 *$ & $91.2(1)$ & $92.8(1)$ & $92.1(2)$ \\
\hline $\mathrm{O} 1-\mathrm{Cu}-\mathrm{N} 1$ & $91.9(1)$ & $94.63(8)$ & $94.6(1)$ \\
\hline O1-Cu-N1* & 168.1(1) & $160.46(8)$ & $161.7(1)$ \\
\hline $\mathrm{O} 1 *-\mathrm{Cu}-\mathrm{N} 1$ & $168.1(1)$ & $160.46(8)$ & $161.7(1)$ \\
\hline $\mathrm{O} 1{ }^{*}-\mathrm{Cu}-\mathrm{N} 1 *$ & $91.9(1)$ & $94.63(8)$ & $94.6(1)$ \\
\hline $\mathrm{O} 3-\mathrm{Cu}-\mathrm{O} 1$ & $95.20(8)$ & & \\
\hline $\mathrm{O} 3-\mathrm{Cu}-\mathrm{O} 1 *$ & $95.20(8)$ & & \\
\hline $\mathrm{O} 3-\mathrm{Cu}-\mathrm{N} 1$ & $96.0(1)$ & & \\
\hline O3-Cu-N1* & $96.0(1)$ & & \\
\hline $\begin{array}{l}\mathrm{O} 1-\mathrm{O} 1 *-\mathrm{N} 1 *-\mathrm{N} 1 \text { and } \\
\mathrm{C} 4-\mathrm{C} 5-\mathrm{C} 6-\mathrm{C} 7-\mathrm{C} 8-\mathrm{C} 9\end{array}$ & 18.744 & 23.856 & 23.829 \\
\hline \multicolumn{2}{|c|}{$\begin{array}{l}\mathrm{O} 1-\mathrm{O} 1 *_{-} \mathrm{N} 1 *_{-\mathrm{N}} 1 \text { and } \\
\mathrm{C} 4 *_{-\mathrm{C}} *_{-} \mathrm{C} 6 *_{-} \mathrm{C} 7 *_{-} \mathrm{C} 8 *_{-} \mathrm{C} 9 * 18.744\end{array}$} & 23.856 & 23.829 \\
\hline
\end{tabular}


TABLE 4 Phase Transition Tenperature and Enthalpy Changes for $\left[\mathrm{Cu}\left(\left(4-\mathrm{C}_{n} \mathrm{H}_{2 n+1} \mathrm{O}\right)_{2}\right.\right.$ salen) $](n=3$ $(\mathbf{1}), 4(2), 6(3), 8(4), 10(5), 12(6), 14(7), 16(8), 18(9)$, and $20(\mathbf{1 0}))^{\mathrm{a}}$

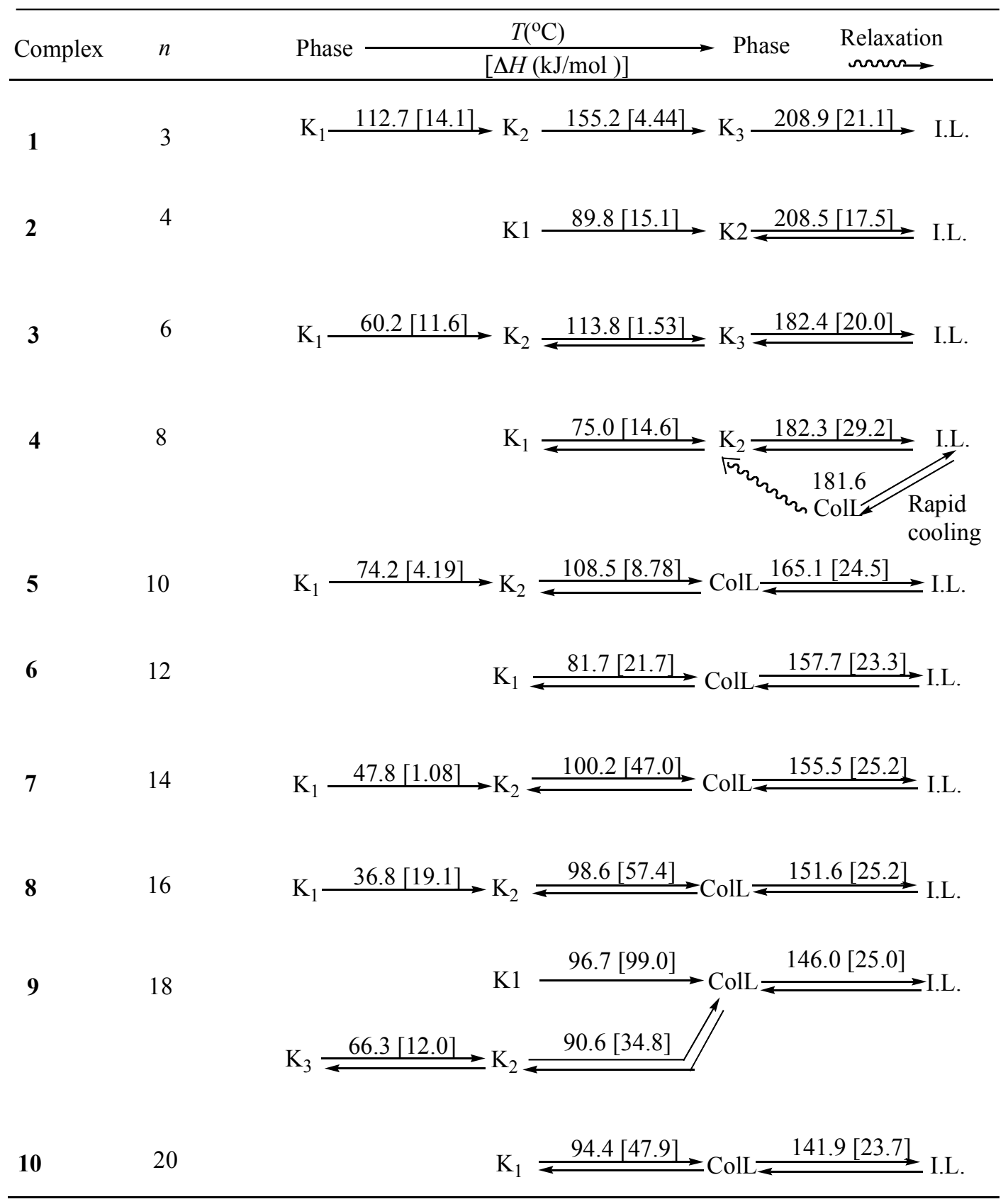

aPhase nomenclature: $\mathrm{K}=$ crystal, $\mathrm{M}=$ mesophase and I.L.=isotropic liquid. 
TABLE 5 X-ray Data for the Mesophase ColL of $\left[\mathrm{Cu}\left(\left(4-\mathrm{C}_{n} \mathrm{H}_{2 n+1} \mathrm{O}\right)_{2}\right.\right.$ salen) $](n=10(5)$, 12 (6), 14 (7), 16 (8), 18 (9), 20 (10))

\begin{tabular}{|c|c|c|c|c|c|c|}
\hline \multirow{2}{*}{ Complex } & \multirow{2}{*}{$n$} & \multirow{2}{*}{ Lattice parameter } & \multirow{2}{*}{ Peak No. } & \multicolumn{2}{|c|}{ Spacing $(\AA)$} & \multirow{2}{*}{$\begin{array}{l}\text { Miller indices } \\
\quad(h k l)\end{array}$} \\
\hline & & & & Observed & Calculated & \\
\hline \multirow[t]{5}{*}{5} & \multirow[t]{5}{*}{10} & $c=25.5$ & 1 & 25.5 & 25.5 & (001) \\
\hline & & $h=6.10$ & 2 & 12.9 & 12.8 & $(002)$ \\
\hline & & at $160^{\circ} \mathrm{C}$ & 3 & 8.56 & 8.50 & $(003)$ \\
\hline & & & 4 & 6.10 & - & $(100)$ \\
\hline & & & 5 & ca. 4.7 & - & $\#$ \\
\hline \multirow[t]{5}{*}{6} & \multirow[t]{5}{*}{12} & $c=29.4$ & 1 & 29.4 & 29.4 & $(001)$ \\
\hline & & $h=6.10$ & 2 & 14.6 & 14.7 & $(002)$ \\
\hline & & at $150^{\circ} \mathrm{C}$ & 3 & 9.73 & 9.80 & (003) \\
\hline & & & 4 & 6.10 & - & $(100)$ \\
\hline & & & 5 & ca. 4.7 & - & \# \\
\hline \multirow[t]{5}{*}{7} & \multirow[t]{5}{*}{14} & $c=32.2$ & 1 & 32.2 & 32.2 & $(001)$ \\
\hline & & $h=6.02$ & 2 & 16.1 & 16.1 & $(002)$ \\
\hline & & at $140^{\circ} \mathrm{C}$ & 3 & 10.7 & 10.7 & $(003)$ \\
\hline & & & 4 & 6.02 & - & $(100)$ \\
\hline & & & 5 & ca. 4.7 & - & $\#$ \\
\hline \multirow[t]{5}{*}{8} & \multirow[t]{5}{*}{16} & $c=35.6$ & 1 & 35.6 & 35.6 & $(001)$ \\
\hline & & $h=6.10$ & 2 & 17.7 & 17.8 & (002) \\
\hline & & at $140^{\circ} \mathrm{C}$ & 3 & 11.7 & 11.9 & $(003)$ \\
\hline & & & 4 & 6.10 & - & $(100)$ \\
\hline & & & 5 & ca. 4.5 & - & \# \\
\hline \multirow[t]{5}{*}{9} & \multirow[t]{5}{*}{18} & $c=38.4$ & 1 & 38.4 & 38.4 & $(001)$ \\
\hline & & $h=6.01$ & 2 & 19.1 & 19.2 & $(002)$ \\
\hline & & at $140^{\circ} \mathrm{C}$ & 3 & 12.7 & 12.8 & $(003)$ \\
\hline & & & 4 & 6.01 & - & $(100)$ \\
\hline & & & 5 & ca. 4.5 & - & $\#$ \\
\hline \multirow[t]{5}{*}{10} & \multirow[t]{5}{*}{20} & $c=41.2$ & 1 & 41.2 & 41.2 & $(001)$ \\
\hline & & $h=6.12$ & 2 & 20.6 & 20.6 & (002) \\
\hline & & at $130^{\circ} \mathrm{C}$ & 3 & 13.7 & 13.7 & (003) \\
\hline & & & 4 & 6.12 & - & (100) \\
\hline & & & 5 & ca.4.5 & - & $\#$ \\
\hline
\end{tabular}

\#: Halo of the melton alkoxy chains. 


\section{Figure captions}

FIGURE 1. (a) Molecular structures of $2 \cdot \mathrm{H}_{2} \mathrm{O}$. (b) Crystal packing diagram of $2 \cdot \mathrm{H}_{2} \mathrm{O}$, viewed along the $\mathrm{c}$ axis. Hydrogen atoms are omitted for clarity.

FIGURE 2. (a) Molecular structures of 6. (b) Crystal packing diagrams of 6, viewed along the $a$ axis $(\mathrm{b}(1))$ and down the $b$ axis $(\mathrm{b}(2))$. Hydrogen atoms are omitted for clarity. Dashed and solid lines indicate two different distances of $\mathrm{Cu}-\mathrm{Cu}$ and the van der Waals interaction among the salen moieties, respectively.

FIGURE 3. (a) Molecular structures of 4. (b) Crystal packing diagrams of 4, viewed along the $a$ axis ( $(\mathrm{b}(1))$ and down the $b$ axis $(\mathrm{b}(2))$. Hydrogen atoms are omitted for clarity. Dashed and solid lines indicate two different distances of $\mathrm{Cu}-\mathrm{Cu}$ and the van der Waals interaction among the salen moieties, respectively.

FIGURE 4. Polarized optical micrograph of the ColL mesophase of $\mathbf{1 0}(n=20)$ at $130{ }^{\circ} \mathrm{C}$ on cooling the I.L. phase from $145^{\circ} \mathrm{C}$.

FIGURE 5. X-ray diffraction patterns of the ColL mesophases of $7(n=14)$ at $140{ }^{\circ} \mathrm{C}$.

FIGURE 6. The $n$ ( $n=$ number of carbon atoms in the alkoxy chain) dependence of the lattice constants, $h$ and $c$ for the $\mathrm{Cu}(\mathrm{II}) 4$-alkoxysalen complexes. 
FIGURE 7. Schematic representation of the ColL mesophase for $\left[\mathrm{Cu}\left(\left(4-\mathrm{C}_{n} \mathrm{H}_{2 n+1} \mathrm{O}\right)_{2}\right.\right.$ salen $\left.)\right]$ $(n=10(\mathbf{5}), 12(\mathbf{6}), 14(7), 16(\mathbf{8}), 18(\mathbf{9}), 20(\mathbf{1 0}))$.

FIGURE 8. The $n$ ( $n=$ the number of carbon atoms in the alkoxy chain) dependence of the phase transition temperature for the $\mathrm{Cu}(\mathrm{II})$ 4-alkoxysalen complexes (red) and $\mathrm{Ni}(\mathrm{II})$ 4-alkoxysalen complexes (black). 


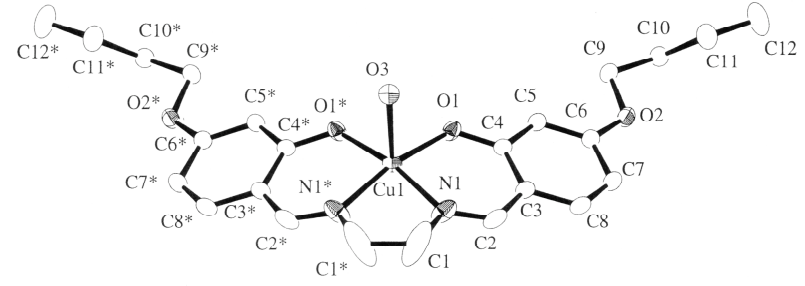

(1)

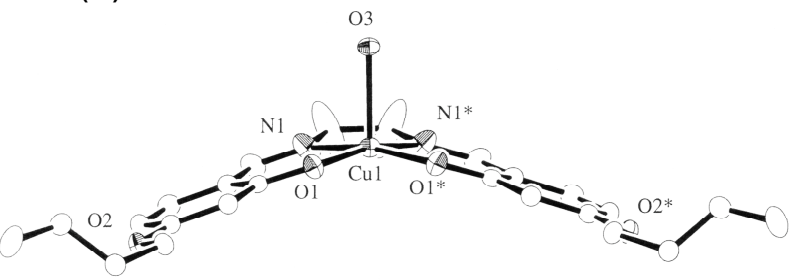

(2)

(a)

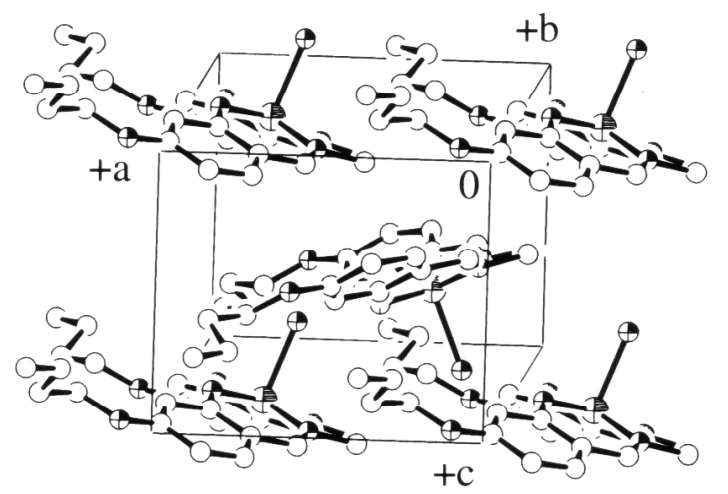

(b)

Figure. 1 


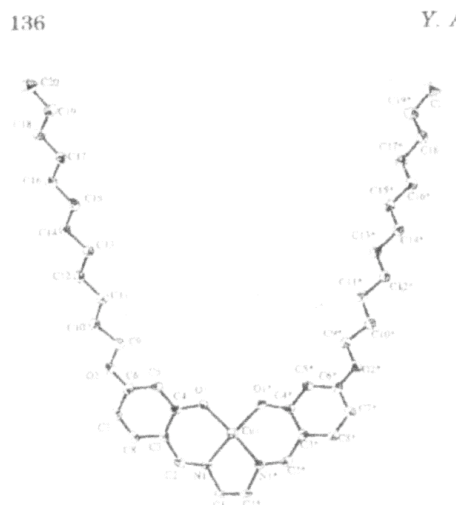

(a) (1)

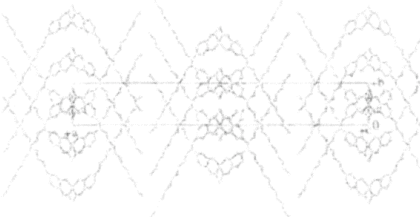

(1)

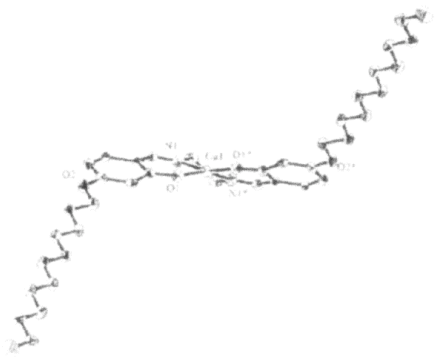

(2)

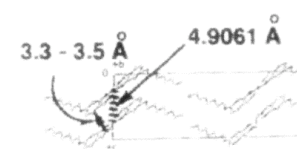

(2)

Figure 2 


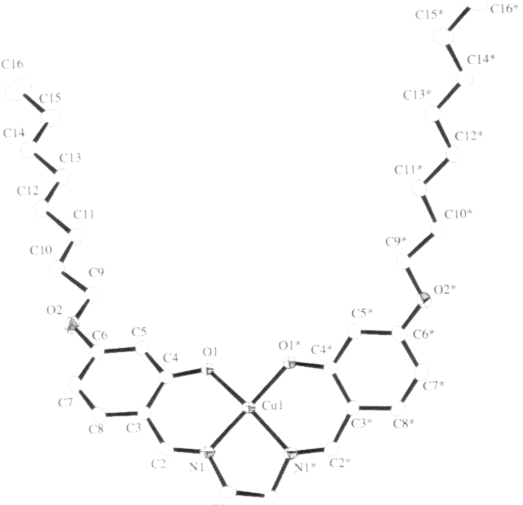

(a)

(1)

(b)

(1)

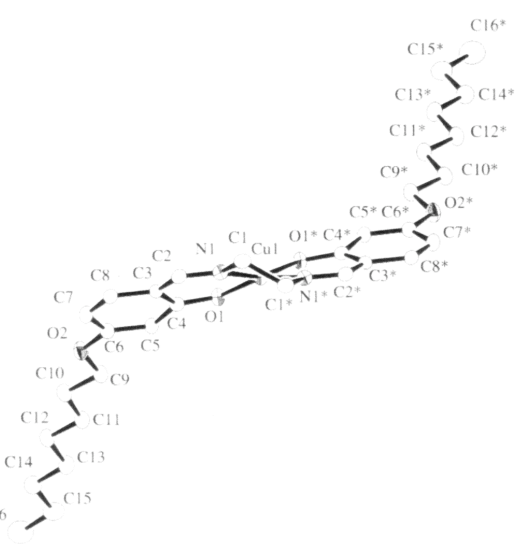

(2)

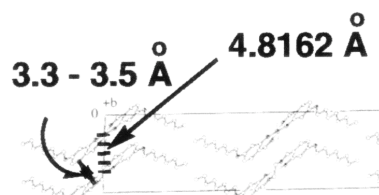

(2)

Figure 3 


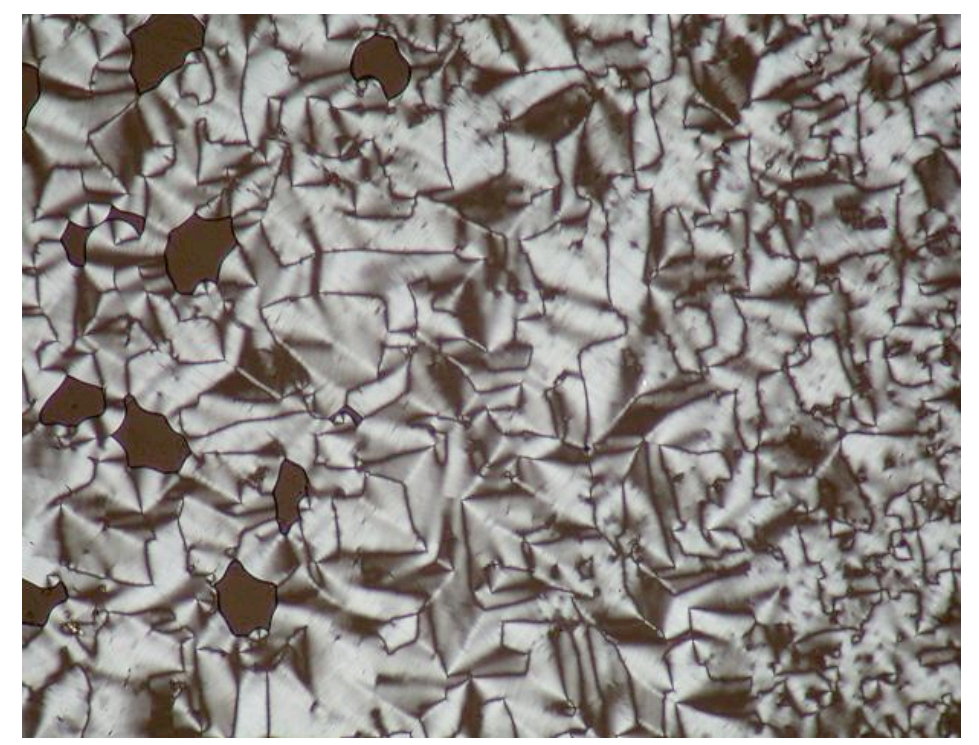

Figure 4 


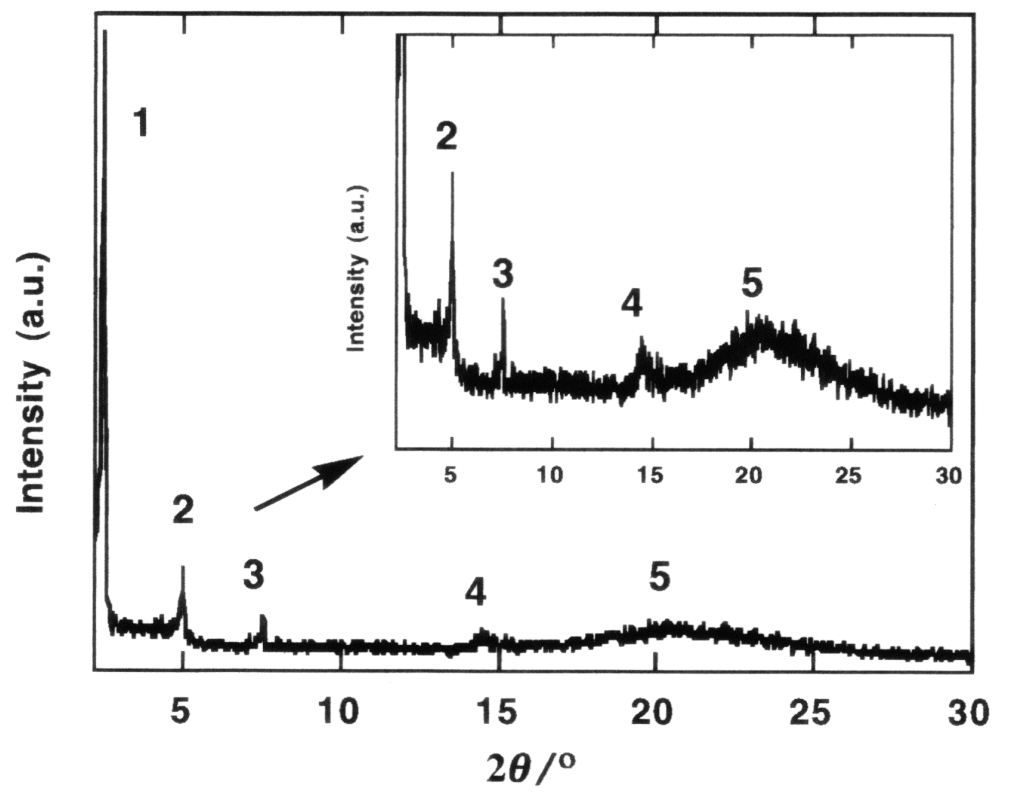

Figure 5 


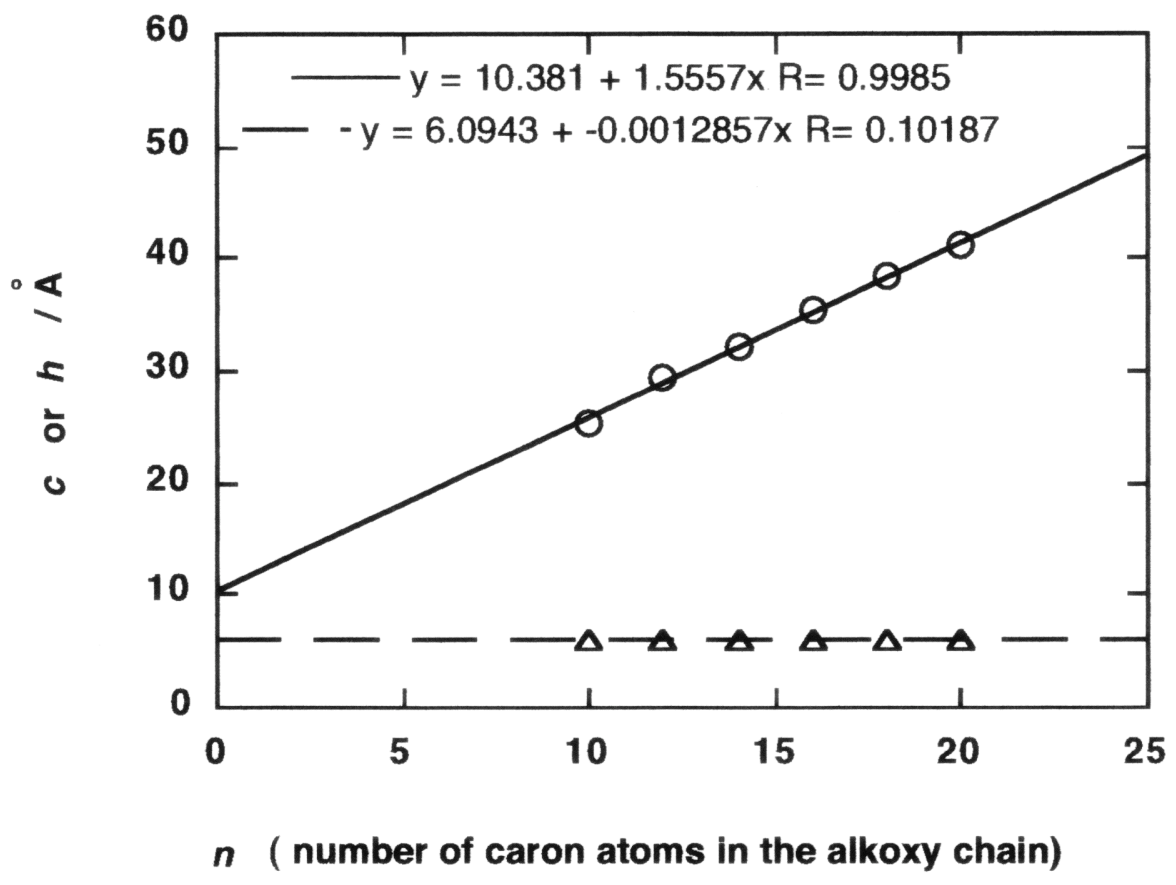

Figure 6 


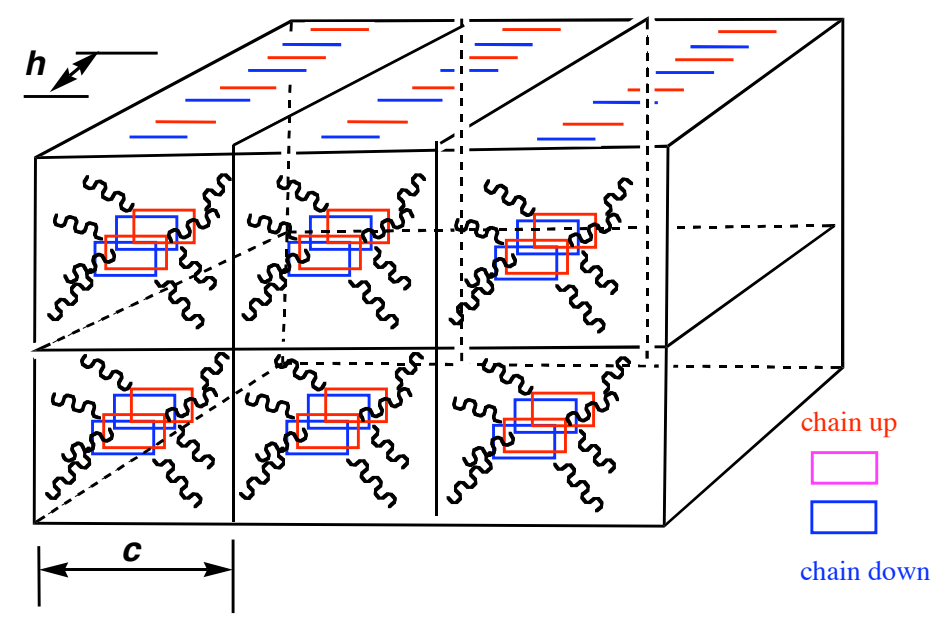

ColL Mesophase

Figure 7 


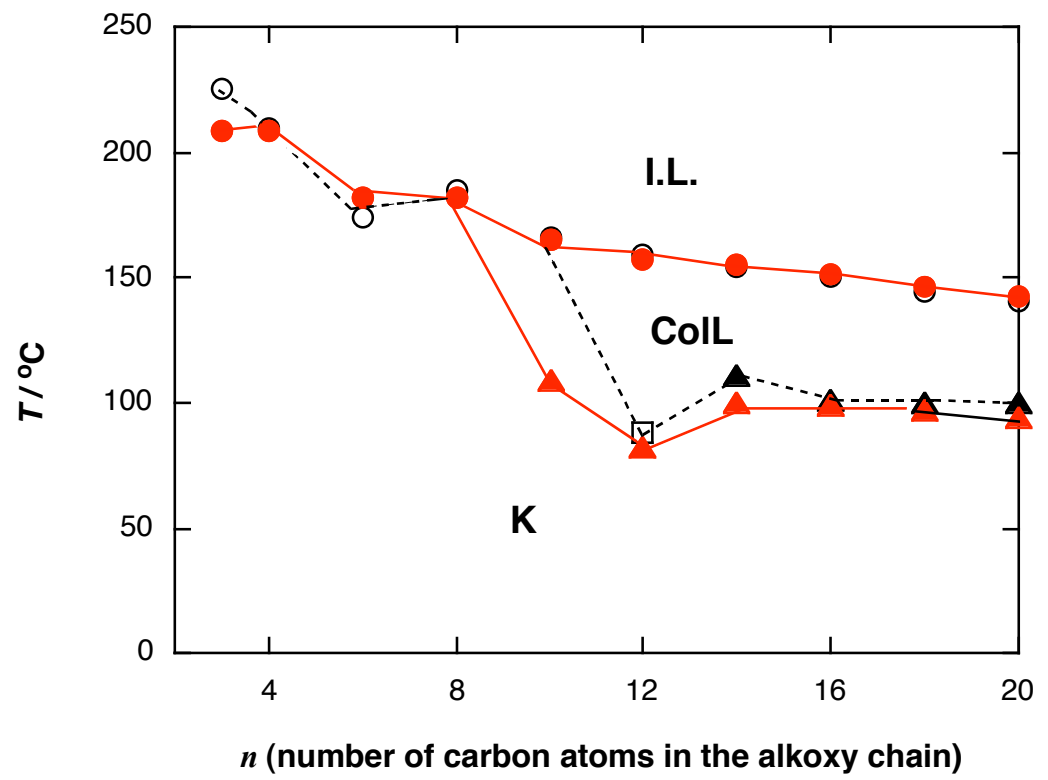

Figure 8 